\title{
Acúmulo de forragem e valor nutritivo do híbrido de Urochloa 'BRS RB331 Ipyporã' sob pastejo intermitente
}

\author{
Joilson Roda Echeverria( ${ }^{(1)}$, Valéria Pacheco Batista Euclides ${ }^{(2)}$, André Fischer Sbrissia(1), \\ Denise Baptaglin Montagner ${ }^{(2)}$, Rodrigo Amorim Barbosa ${ }^{(2)}$ e Nayana Nazareth Nantes ${ }^{(3)}$
}

(1)Universidade do Estado de Santa Catarina, Centro de Ciências Agroveterinárias, Departamento de Zootecnia, CEP $88520-000$ Lages, SC,
Brasil. E-mail: joilson_echeverria@hotmail.com, sbrissia@cav.udesc.br ${ }^{(2)}$ Embrapa Gado de Corte, Caixa Postal 154, CEP 79002-970 Campo
Grande, MS, Brasil. E-mail: valeria.pacheco@embrapa.br, denise.montagner@embrapa.br, rodrigo.barbosa@embrapa.br ${ }^{(3)}$ Universidade
Federal de Mato Grosso do Sul, Caixa Postal 549, CEP 79070-900 Campo Grande, MS, Brasil. E-mail: nayzootecnia@hotmail.com

Resumo - O objetivo deste trabalho foi avaliar o acúmulo de forragem e o valor nutritivo do híbrido de Urochloa 'BRS RB331 Ipyporã' (Urochloa brizantha x Urochloa ruziziensis) submetido à pastejo intermitente. Os tratamentos corresponderam às combinações entre as condições de pré-pastejo, interceptação de $95 \%$ da luz incidente e máxima interceptação de luz, e as de pós-pastejo, 10 e $15 \mathrm{~cm}$ de altura de resíduo, em delineamento de blocos ao acaso, em arranjo fatorial 2x2, com quatro repetições. Pastos manejados com $95 \%$ de interceptação da luz apresentaram maior taxa de acúmulo de forragem, proporção de folhas, relação folha:colmo, teor de proteína bruta e densidade populacional de perfilhos basilares ( $\mathrm{DPPb}$ ), em comparação àqueles manejados com máxima interceptação da luz. Pastos manejados com $15 \mathrm{~cm}$ de altura do resíduo apresentaram maior $\mathrm{DPPb}$ do que os manejados com $10 \mathrm{~cm}$ e apresentaram pequena variação de $\mathrm{DPPb}$ entre as estações do ano avaliadas, independentemente do tratamento. Pastos do híbrido interespecífico de Urochloa 'BRS RB331 Ipyporã' apresentam maior acúmulo de forragem e maiores teores de proteína bruta e digestibilidade in vitro da matéria orgânica e menores teores de fibra em detergente neutro na fração folha, quando manejados com $95 \%$ de IL nas condições de pré-pastejo, com $30 \mathrm{~cm}$ de altura do dossel, associada com $15 \mathrm{~cm}$ de altura de resíduo.

Termos para indexação: Brachiaria brizantha, Brachiaria ruziziensis, altura do dossel, densidade populacional de perfilhos, híbrido de braquiária, manejo de pastejo.

\section{Forage accumulation and nutritive value of the Urochloa interspecific hybrid 'BRS RB331 Ipyporã' under intermittent grazing}

\begin{abstract}
The objective of this work was to evaluate the forage accumulation and nutritional value of the Urochloa hybrid 'BRS RB331 Ipyporã' (Urochloa brizantha x Urochloa ruziziensis) subjected to intermittent grazing. The treatments corresponded to combinations of the pre-grazing conditions, interception of $95 \%$ of incident light and maximum light interception, and of the post-grazing heights, 10 and $15 \mathrm{~cm}$, in a randomized complete block design with a $2 \times 2$ factorial arrangement and four replicates. Pastures grazed at $95 \%$ of light interception showed higher forage accumulation rate, proportion of leaves, leaf:stem ratio, crude protein content, and basal tiller population density (BTPD), in comparison with those managed at maximum light interception. Pastures managed with post-grazing heights of $15 \mathrm{~cm}$ showed greater BTPD than those managed at $10 \mathrm{~cm}$ and showed a slightly variation in BTPD among the evaluated seasons of the year, regardless of the treatment. Pastures of the interspecific hybrid of Urochloa 'BRS RB331 Ipyporã' show greater forage accumulation and higher crude protein content and in vitro organic matter digestibility, and lower content of neutral detergent fiber in the leaf fraction, when managed with $95 \%$ LI under pre-grazing conditions of $30-\mathrm{cm}$ sward height, associated with a post-grazing $15-\mathrm{cm}$ sward height.
\end{abstract}

Index terms: Brachiaria brizantha, Brachiaria ruziziensis, sward height, tiller population density, brachiaria hybrid, grazing management.

\section{Introdução}

Nas últimas décadas, o desenvolvimento de novas cultivares de plantas forrageiras tem contribuído para ampliar o leque de opções aos produtores ante as mais diversas demandas, como plantas tolerantes ao encharcamento, sombreamento, cultivares mais produtivas, maior tolerância a doenças e pragas, entre outros. Particularmente quanto às pragas, existe uma demanda recorrente por variedades que apresentem maior tolerância e/ou resistência às cigarrinhas-das-pastagens, que têm-se constituído 
problema relevante para a bovinocultura brasileira. Nesse sentido, o híbrido interespecífico de Urochloa 'BRS RB331 Ipyporã' foi desenvolvido pelo cruzamento entre um genótipo de Urochloa ruziziensis (syn. Brachiaria ruziziensis) e um acesso de Urochloa brizantha (syn. Brachiaria brizantha), em que se buscou introduzir a resistência a essa praga (Brasil, 2015) na nova cultivar, além de manter as boas produções de forragem e valor nutritivo presentes em seus genitores.

Pesquisas sobre o manejo de plantas forrageiras, em pastagens com gramíneas de clima tropical, têm mostrado a existência de uma condição ideal para a interrupção do período de rebrotação dos pastos que, geralmente, está associada ao momento em que o dossel intercepta cerca de $95 \%$ da radiação fotossinteticamente ativa (RFA) (Carnevalli et al., 2006; Barbosa et al., 2007). Estes autores utilizaram diferentes equipamentos para quantificar a RFA, alguns deles, no entanto, não medem integralmente esse valor, mas apresentam indicação de que a partir do momento em que o dossel intercepta $95 \%$ da radiação solar incidente, o pasto apresenta maior proporção de folhas e menor proporção de colmos e material morto do que os pastos manejados além deste limite.

As combinações possíveis entre frequência, representadas pela interceptação da radiação solar pelo dossel e pela intensidade de pastejo, caracterizadas pela altura de resíduo, são capazes de promover respostas bastante distintas em plantas forrageiras sob pastejo. Estas respostas são determinadas pelas alterações do índice de área foliar (IAF) do dossel, que pode ser modificado por meio de variações da densidade populacional de perfilhos (Matthew et al., 1995) e pela ontogenia em perfilhos individuais (Berone et al., 2007), o que afeta diretamente o acúmulo de forragem e a estrutura do dossel forrageiro.

A condição em que o dossel intercepta cerca de $95 \%$ da RFA é válida para um amplo espectro de espécies de plantas forrageiras (Carnevalli et al., 2006; Pedreira et al., 2009; Zanini et al., 2012), no entanto, em caso de lançamento de novos materiais, é importante que eles já venham com indicativos adequados de manejo, a fim de minimizar possíveis insucessos.

O objetivo deste trabalho foi avaliar o acúmulo de forragem e o valor nutritivo do híbrido de Urochloa 'BRS RB331 Ipyporã' (Urochloa brizantha x Urochloa ruziziensis) submetido à pastejo intermitente.

\section{Material e Métodos}

O experimento foi realizado na Embrapa Gado de Corte, em Campo Grande, MS, 20 $27^{\circ} \mathrm{S}$ e $54^{\circ} 37^{\prime} \mathrm{W}$, a $530 \mathrm{~m}$ de altitude, de novembro de 2012 a abril de 2014 . O clima da região é descrito, segundo a classificação de Köppen-Geiger, como pertencente à faixa de transição entre $\mathrm{Cfa}$ e Aw tropical úmido. Os dados meteorológicos foram coletados durante o período experimental (Figura 1). Com base nas temperaturas médias mensais e na precipitação pluvial mensal acumulada, calculou-se o balanço hídrico mensal, tendo-se considerado uma CAD de $75 \mathrm{~mm}$ (Figura 2).

O solo da área experimental é classificado como Latossolo Vermelho distrófico (Santos et al., 2013). Antes do estabelecimento dos pastos, realizou-se a análise química da camada de $0-20 \mathrm{~cm}$ do solo, que apresentou os seguintes valores: $\mathrm{pH}\left(\mathrm{CaCl}_{2}\right), 5,34 ; \mathrm{Ca}$, $3,28 \mathrm{cmol}_{\mathrm{c}} \mathrm{dm}^{-3} ; \mathrm{Mg}, 1,41 \mathrm{cmol}_{\mathrm{c}} \mathrm{dm}^{-3} ; \mathrm{Al}, 0,03 \mathrm{cmol}_{\mathrm{c}} \mathrm{dm}^{-3}$; $\mathrm{H}+\mathrm{Al}, 4,37 \mathrm{cmol}_{\mathrm{c}} \mathrm{dm}^{-3} ; \mathrm{K}, 108,5 \mathrm{mg} \mathrm{dm}^{-3}$; saturação por bases, 53,1\%; matéria orgânica, 3,48\%; e P (em Mehlich-1), 7,76 $\mathrm{mg} \mathrm{dm}^{-3}$. Antes da implantação dos pastos, realizou-se a adubação do solo com $70 \mathrm{~kg} \mathrm{ha}^{-1}$ de $\mathrm{P}_{2} \mathrm{O}_{5}$ e de $\mathrm{K}_{2} \mathrm{O}$.

Os pastos constituídos do híbrido de Urochloa 'BRS RB331 Ipyporã' foram estabelecidos em janeiro de 2012, tendo-se utilizado $5 \mathrm{~kg} \mathrm{ha}^{-1}$ de sementes puras viáveis, em sistema de plantio direto, com espaçamento de $30 \mathrm{~cm}$ entre linhas. Em abril de 2012, utilizou-se taxa de lotação baixa e, em novembro do mesmo ano, realizou-se o corte de uniformização a $15 \mathrm{~cm}$ do solo. $\mathrm{O}$ monitoramento das condições do pasto iniciou-se em 27/11/2012. A adubação nitrogenada foi realizada nos dois anos de avaliação, com $150 \mathrm{~kg} \mathrm{~N}$ (ureia) ha ${ }^{-1}$ por ano, durante o período chuvoso (entre novembro e março), dividida em três aplicações por período.

A área experimental foi dividida em quatro blocos de $1.960 \mathrm{~m}^{2}$, com quatro piquetes de $490 \mathrm{~m}^{2}$ cada, divididos por cerca elétrica. Os tratamentos constituíram-se da combinação entre duas frequências de desfolhação, representadas pelo tempo necessário para que o dossel forrageiro interceptasse $95 \%$ da radiação incidente e pela máxima interceptação (ILmáx), assim considerada quando, em duas avaliações consecutivas, o dossel interceptasse $98 \%$ da radiação incidente, e duas intensidades de pastejo, representadas pelas alturas de resíduo de 10 e $15 \mathrm{~cm}$. Utilizou-se o delineamento experimental de blocos ao acaso, em um arranjo fatorial $2 \times 2$, com quatro repetições. Como não existe 
na literatura nenhuma recomendação de manejo para a cultivar avaliada (pastos manejados sob lotação contínua ou intermitente), os critérios utilizados para a escolha das alturas de resíduo foram baseados, em parte, no manejo recomendado para cultivares de Urochloa brizantha, um dos genitores do híbrido 'BRS RB331 Ipyporã'. Para algumas cultivares de U. brizantha - 'Marandu' e 'Xaraés' -, há indicações de

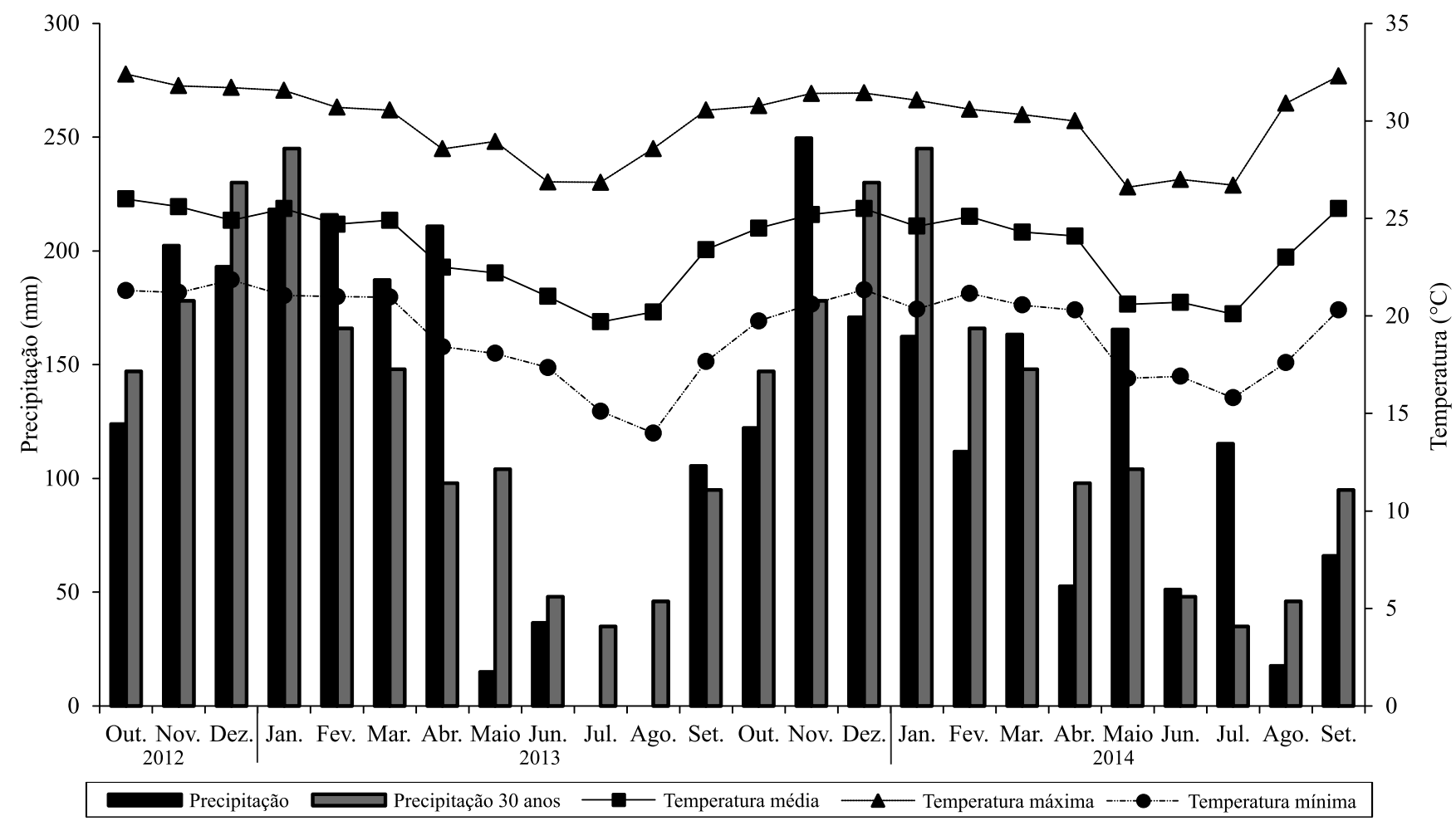

Figura 1. Temperaturas média, mínima e máxima e precipitação mensal, durante o período experimental.

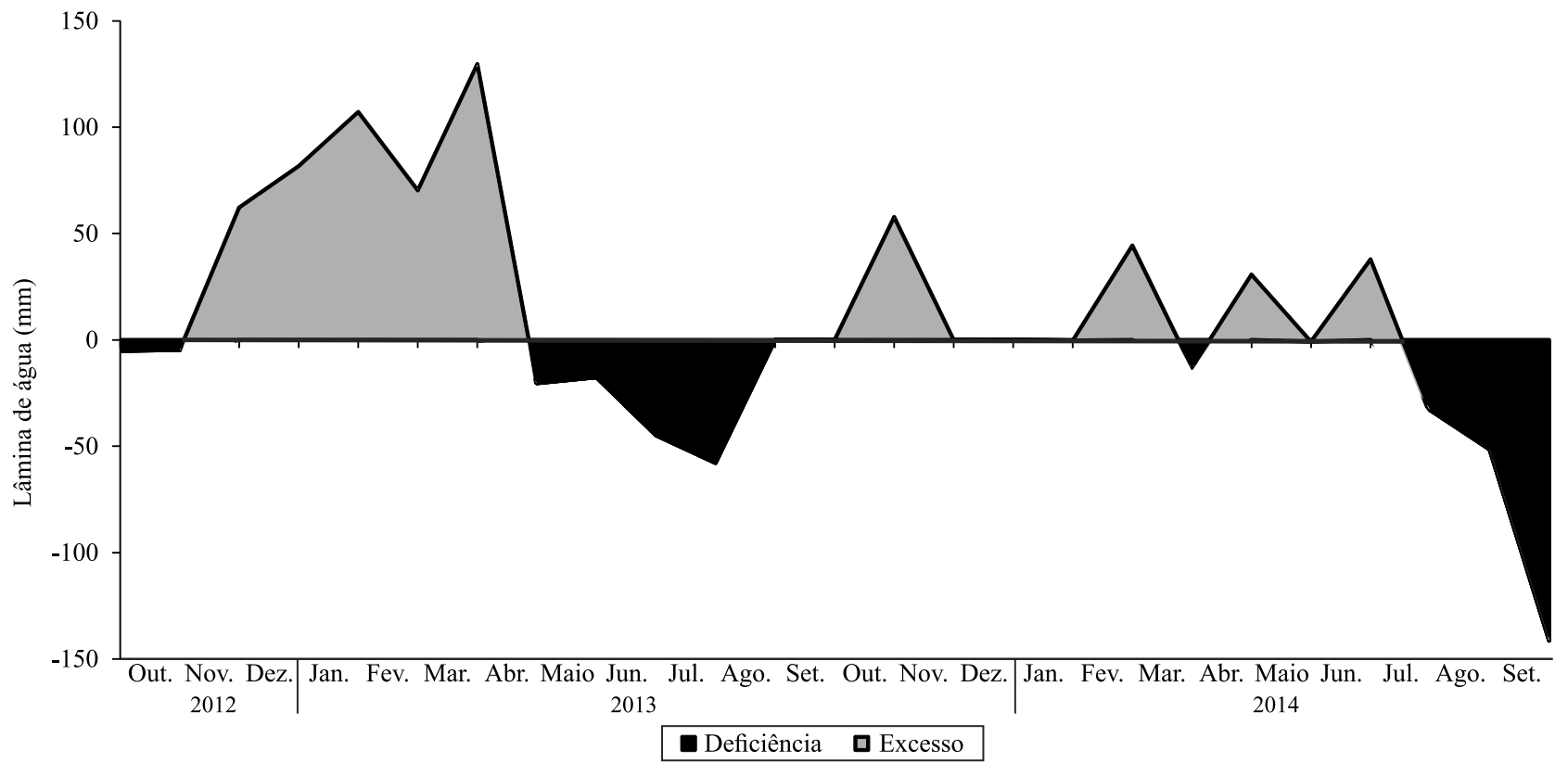

Figura 2. Balanço hídrico mensal durante o período experimental, tendo-se utilizado $75 \mathrm{~mm}$ de capacidade de armazenamento de água no solo (CAD). 
que, sob lotação intermitente, as alturas em pós-pastejo devem ser de $15 \mathrm{~cm}$ (Giacomini et al., 2009; Pedreira et al., 2009). Como o híbrido 'BRS RB331 Ipyporã' apresenta porte médio, semelhante aos seus genitores, optou-se por avaliar dois tipos de manejos, um relativamente moderado ( $15 \mathrm{~cm}$ de altura de resíduo) e outro relativamente severo ( $10 \mathrm{~cm}$ de altura de resíduo).

O método de pastejo utilizado foi o de lotação intermitente, com taxa de lotação variável. Os intervalos entre pastejo corresponderam ao período de tempo necessário para que o dossel forrageiro interceptasse $95 \%$ da radiação incidente ou a máxima interceptação de luz, conforme o tratamento, e os períodos de ocupação corresponderam ao período de tempo necessário para que o resíduo pós-pastejo fosse atingido de acordo com o tratamento, que era de 10 ou $15 \mathrm{~cm}$ de altura. $\mathrm{O}$ rebaixamento dos pastos foi realizado por bovinos machos cruzados, com peso vivo médio de $250 \mathrm{~kg}$. Os animais eram conduzidos aos piquetes quando o dossel alcançava a condição pré-pastejo preconizada, e eram retirados quando a altura de resíduo pretendida era alcançada. $\mathrm{O}$ número de animais em cada piquete foi determinado de acordo com a meta de altura de resíduo pretendido, para manter um período de ocupação inferior a sete dias.

A interceptação luminosa foi medida por meio de um aparelho analisador de dossel - AccuPAR Linear PAR/LAI ceptometer, Model PAR - 80 (Decagon Devices Inc., Pulmann, WA, EUA) seguindo as recomendações de uso do fabricante. $\mathrm{O}$ aparelho utilizado foi um ceptômetro linear, constituído por um microprocessador datalogger, que interpreta os sinais dos sensores ( 80 sensores independentes), por meio do cálculo do valor médio de cada segmento especificado, localizado na sonda $(86,5 \mathrm{~cm}$ de comprimento), que mensura a RFA entre os valores de 400-700 nm. As leituras foram realizadas em 20 pontos aleatórios dentro do piquete, que consistiam em uma medida acima do dossel e outra no nível do solo, e as medições seguiam padrões de horário e condições meteorológicas, das 9:00 às 11:00 h da manhã, período do dia em que as condições de nebulosidade do céu eram mais uniformes, preferencialmente de céu aberto. Durante a fase de rebrotação, as leituras foram realizadas a cada semana. Quando os níveis de interceptação de luz (IL) estavam próximos dos valores das metas de pré-pastejo, aumentou-se a frequência de monitoramento, com leituras realizadas a cada dois dias, até que a meta fosse atingida. A altura do pasto foi determinada com uma régua graduada em centímetros, em 20 pontos aleatórios por piquete, em que a altura de cada ponto correspondeu à altura média do dossel em torno da régua. Realizaram-se as medidas de altura nas condições de pré- e pós-pastejo.

A densidade populacional de perfilhos basilares $(\mathrm{DPPb})$ foi determinada por meio da contagem em três pontos por piquete, representativos da condição média dos pastos. A contagem foi realizada em cada ciclo, na condição de pré-pastejo, com auxílio de um quadro metálico com área de $0,25 \mathrm{~m}^{2}$. A massa de forragem foi quantificada nas condições de pré- e pós-pastejo, a partir de quatro amostras coletadas em $1 \mathrm{~m}^{2}$ por piquete, que foram cortadas rentes ao solo com auxílio de segadeira costal. Para avaliação da massa de matéria seca de forragem, cada amostra foi dividida em duas, uma parte acondicionada em saco de papel e seca em estufa de ventilação forçada de ar a $65^{\circ} \mathrm{C}$, até obtenção de massa constante; a outra parte foi separada manualmente em lâmina foliar, colmo (colmo + bainha) e material morto. Após a separação, os componentes foram secos em estufa de circulação forçada de ar a $65^{\circ} \mathrm{C}$, até obtenção de massa constante.

A taxa de acúmulo de forragem foi determinada por meio da diferença entre os valores de massa de forragem no pré-pastejo atual e no pós-pastejo anterior de cada piquete, dividida pelo número de dias entre avaliações. $\mathrm{O}$ valor nutritivo da forragem foi estimado nas frações folha e colmo dos componentes morfológicos da forragem, no pré-pastejo, com uso do sistema de espectrofotometria de reflectância no infravermelho proximal (NIRS - near-infrared spectroscopy). Estimaram-se os teores de proteína bruta (PB), fibra em detergente neutro (FDN), digestibilidade in vitro da matéria orgânica (DIVIMO) e lignina em detergente ácido (LDA).

A análise estatística dos dados foi realizada com o procedimento Proc Mixed do pacote estatístico SAS (SAS Institute Inc., Cary, EUA). Os dados foram agrupados nos seguintes períodos: verão12 (19/12/2012 a 20/3/2013); outono13 (21/3 a 20/6/2012); inverno13 (21/6 a 22/9/2013); primavera13 (23/9 a 20/12/2013); verão14 (21/12 a 18/3/2014) e outono14 (19/3 a 22/4/2014). Utilizou-se um modelo matemático, que continha o efeito aleatório de bloco e os efeitos fixos de interceptação luminosa, altura do resíduo e período do ano, bem como suas interações. As médias foram comparadas pelo teste de Tukey, a 5\% de probabilidade. 


\section{Resultados e Discussão}

As metas em pré-pastejo foram alcançadas, e o tratamento de $95 \%$ de IL apresentou média de 95,1\%, e o de ILmáx de $98 \%$, que corresponderam à altura de dossel média de $29,6 \mathrm{~cm}$ e $41,5 \mathrm{~cm}$, respectivamente. De acordo com Carnevalli et al. (2006), Trindade et al. (2007) e Pedreira et al. (2009), há dificuldades para o registro de valores absolutos de IL acima de $99 \%$ em ambientes de pastagens, uma vez que é muito difícil criar condições para que toda luz incidente seja interceptada pelo pasto ( $100 \%$ de IL).

A altura de resíduo de $15 \mathrm{~cm}$ foi alcançada, independentemente de tratamento, com médias de $14,8 \mathrm{~cm}$ e $15,2 \mathrm{~cm}$ para os tratamentos de $95 \%$ de IL e ILmáx, respectivamente. Entretanto, houve dificuldade para o rebaixamento dos pastos para a altura de $10 \mathrm{~cm}$ de resíduo, principalmente quando a meta em pré-pastejo foi de ILmáx, com médias de $11,3 \mathrm{~cm}$ e $13,3 \mathrm{~cm}$ para os tratamentos de $95 \%$ de IL e ILmáx, respectivamente. Deve-se ressaltar que apesar de os pastos manejados com $10 \mathrm{~cm}$ de altura de resíduo terem apresentado média de altura pós-pastejo real próxima à dos pastos manejados com $15 \mathrm{~cm}$ de altura, a diferença na composição morfológica do

Tabela 1. Massa de forragem (MF) e componentes morfológicos no pré-pastejo e pós-pastejo, taxa de acúmulo de forragem (TAF) e densidade populacional de perfilhos basilares (DPPb), em pastos do híbrido de Urochloa 'BRS RB331 Ipyporã', submetidos a duas alturas em pós-pastejo ${ }^{(1)}$.

\begin{tabular}{|c|c|c|c|}
\hline \multirow[t]{2}{*}{ Variável } & \multicolumn{2}{|c|}{ Altura de resíduo } & \multirow[t]{2}{*}{$\mathrm{p}$} \\
\hline & $10 \mathrm{~cm}$ & $15 \mathrm{~cm}$ & \\
\hline \multicolumn{4}{|c|}{ Pré-pastejo } \\
\hline $\operatorname{MF}\left(\mathrm{kg} \mathrm{ha}^{-1}\right.$ de MS) & $3.573 \mathrm{~A}(92,7)$ & $3.559 \mathrm{~A}(89,2)$ & 0,9070 \\
\hline Folha (\%) & $68 \mathrm{~A}(0,8)$ & $67 \mathrm{~A}(0,8)$ & 0,2228 \\
\hline Colmo (\%) & $19 \mathrm{~A}(0,6)$ & $19 \mathrm{~A}(0,6)$ & 0,5860 \\
\hline Material morto (\%) & $13 \mathrm{~A}(1,7)$ & $14 \mathrm{~A}(1,6)$ & 0,0489 \\
\hline Relação folha:colmo & $3,6 \mathrm{~A}(0,2)$ & $3,5 \mathrm{~A}(0,2)$ & 0,7032 \\
\hline \multicolumn{4}{|c|}{ Pós-pastejo } \\
\hline MF (kg ha-1 de MS) & $1.464 \mathrm{~B}(45,4)$ & $1.755 \mathrm{~A}(54,4)$ & 0,0001 \\
\hline Folha (\%) & 14B $(1,0)$ & $21 \mathrm{~A}(1,0)$ & 0,0001 \\
\hline Colmo $(\%)$ & $29 \mathrm{~A}(1,3)$ & $27 \mathrm{~A}(1,2)$ & 0,2050 \\
\hline Material morto $(\%)$ & $57 \mathrm{~A}(1,7)$ & $52 \mathrm{~B}(1,6)$ & 0,0489 \\
\hline \multicolumn{4}{|c|}{ Taxa de acúmulo } \\
\hline TAF ( $\mathrm{kg} \mathrm{ha}^{-1}$ de MS por dia) & $37,7 \mathrm{~B}(1,3)$ & $43,4 \mathrm{~A}(1,2)$ & 0,0019 \\
\hline \multicolumn{4}{|c|}{ Densidade populacional de perfilhos } \\
\hline $\mathrm{DPPb}$ (perfilhos $\mathrm{m}^{-2}$ ) & $1.088 \mathrm{~B}(26,8)$ & $1.170 \mathrm{~A}(25,4)$ & 0,0201 \\
\hline
\end{tabular}

${ }^{(1)}$ Médias seguidas de letras iguais, nas linhas, não diferem pelo teste Tukey, a 5\% de probabilidade. Valores entre parênteses correspondem ao erro-padrão da média. resíduo mostra o contraste observado entre as metas de resíduo (Tabela 1). Dificuldade semelhante foi relatada por Barbosa et al. (2007), em experimento com capim-tanzânia (Panicum maximum Jacq. 'Tanzânia-1') e por Trindade et al. (2007) com capim-marandu (Urochloabrizantha'Marandu'). Em pastejos realizados menos frequentemente, caso dos pastos manejados em condição de pré-pastejo acima de $95 \%$ de IL, ocorre acentuado alongamento do colmo, no final do período de rebrotação (Carnevalli et al., 2006), o que impõe dificuldades adicionais aos animais para rebaixar os pastos, uma vez que, segundo Orr et al. (2004), animais em pastejo preferem consumir folhas em detrimento de colmos, fazendo com que esses se acumulem ao longo dos ciclos, o que acaba progressivamente por aumentar as alturas de resíduo.

No pré-pastejo, pastos manejados com a ILmáx apresentaram maior massa de forragem, percentagem de colmo e material morto, em comparação àqueles manejados com 95\% de IL (Tabela 2). De forma contrária, pastos manejados com $95 \%$ de IL apresentaram maior percentagem de folha e maior relação folha:colmo do que os pastos manejados

Tabela 2. Massa de forragem (MF) e componentes morfológicos no pré-pastejo e pós-pastejo, taxa de acúmulo de forragem (TAF) e densidade populacional de perfilhos basilares (DPPb), em pastos do híbrido de Urochloa 'BRS RB331 Ipyporã', submetidos a duas frequências de desfolhação(1).

\begin{tabular}{|c|c|c|c|}
\hline \multirow[t]{2}{*}{ Variável } & \multicolumn{2}{|c|}{ Interceptação de luz } & \multirow[t]{2}{*}{$\mathrm{p}$} \\
\hline & $95 \%$ & ILmáx & \\
\hline & \multicolumn{2}{|c|}{ Pré-pastejo } & \\
\hline MF $\left(\mathrm{kg} \mathrm{ha}^{-1}\right.$ de MS $)$ & $3.095 \mathrm{~B}(83,0)$ & $4.037 \mathrm{~A}(99,7)$ & 0,0001 \\
\hline Folha $(\%)$ & $73 \mathrm{~A}(0,8)$ & $62 \mathrm{~B}(0,9)$ & 0,0001 \\
\hline Colmo (\%) & $16 \mathrm{~B}(0,5)$ & $23 \mathrm{~A}(0,6)$ & 0,0001 \\
\hline Material morto $(\%)$ & $11 \mathrm{~B}(0,7)$ & $15 \mathrm{~A}(0,9)$ & 0,0002 \\
\hline \multirow[t]{2}{*}{ Relação folha:colmo } & $4,6 \mathrm{~A}(0,2)$ & $2,7 \mathrm{~B}(0,2)$ & 0,0001 \\
\hline & \multicolumn{2}{|c|}{ Pós-pastejo } & \\
\hline MF $\left(\mathrm{kg} \mathrm{ha}^{-1}\right.$ de MS) & $1.459 \mathrm{~B}(45,4)$ & $1.755 \mathrm{~A}(54,4)$ & 0,0001 \\
\hline Folha $(\%)$ & $20 \mathrm{~A}(0,9)$ & $15 \mathrm{~B}(1,1)$ & 0,0005 \\
\hline Colmo (\%) & $27 \mathrm{~A}(1,1)$ & $30 \mathrm{~A}(1,3)$ & 0,1477 \\
\hline \multirow[t]{2}{*}{ Material morto (\%) } & $53 \mathrm{~A}(1,5)$ & $55 \mathrm{~A}(1,8)$ & 0,2842 \\
\hline & \multicolumn{2}{|c|}{ Taxa de acúmulo } & \\
\hline \multirow[t]{2}{*}{ TAF (kg ha-1 de MS por dia) } & $43,9 \mathrm{~A}(1,2)$ & $37,2 \mathrm{~B}(1,4)$ & 0,0004 \\
\hline & \multicolumn{3}{|c|}{ Densidade populacional de perfilhos } \\
\hline$\underline{\mathrm{DPPb}}\left(\right.$ perfilhos $\left.\mathrm{m}^{-2}\right)$ & $1.187 \mathrm{~A}(26,7)$ & $1.072 \mathrm{~B}(26,6)$ & 0,0023 \\
\hline
\end{tabular}

${ }^{(1)}$ Médias seguidas de letras iguais, nas linhas, não diferem pelo teste Tukey, a 5\% de probabilidade. Valores entre parênteses correspondem ao erro-padrão da média. 
com a ILmáx. A massa de forragem em pré-pastejo foi maior no verão de 2012 e menor na primavera de 2013 (Tabela 3). A percentagem de folha foi menor no inverno de 2013, e a percentagem de colmo foi menor na primavera de 2013, em comparação às demais estações do ano. A proporção de material morto no pré-pastejo foi maior no inverno de 2013, e a relação folha:colmo foi maior na primavera de 2013, em comparação às demais épocas do ano.

No pós-pastejo, os maiores valores de massa de forragem foram observados nos pastos manejado com ILmáx (Tabela 2), fato atribuído justamente à composição da forragem residual, já que os percentuais de colmo e de material morto observados nesse tratamento foram maiores do que em pastos manejados com 95\% de IL. Pastos manejados com $15 \mathrm{~cm}$ de altura de resíduo apresentaram maior massa de forragem e percentagem de folha do que aqueles manejados com $10 \mathrm{~cm}$ (Tabela 1). Em relação à estação do ano, a maior percentagem de folha ocorreu no verão de 2012 e na primavera de 2013, e a menor, no inverno de 2013 (Tabela 3). Observou-se a maior proporção de colmo no verão de 2012, outono de 2013 e verão de 2013, e a menor, no inverno de 2013. A maior proporção de material morto foi observada no inverno de 2013.

A competição por luz entre plantas individuais promove alongamento do colmo, de forma que as folhas sejam projetadas em pontos cada vez mais altos, com o objetivo de alcançar a luz incidente no topo do dossel. Esta alteração da estrutura da planta forrageira pode acarretar a redução do acúmulo de folhas, o que diminui a relação folha:colmo. Carnevalli et al. (2006) e Barbosa et al. (2007) observaram que pastos manejados com frequência de desfolhação acima de 95\% de IL apresentaram aumentos do alongamento de colmos e acúmulo de material morto, em consequência do prolongamento do período de descanso. Além disso, as menores proporções de colmo e as maiores de material morto, no período de inverno, podem ser atribuídas às variações dos fatores de crescimento nos períodos mais frios e secos do ano, as quais restringem o crescimento, mas aumentam a proporção de tecidos mortos na base do dossel.

Verificou-se uma consequência direta das variações entre tratamentos na taxa de acúmulo de forragem (TAF), para os valores de massa de forragem tanto em pré- quanto em pós-pastejo. Pastos manejados com 95\% de IL apresentaram maior TAF do que aqueles manejados com ILmáx (Tabela 2). Além disso, os maiores valores foram observados em pastos rebaixados até $15 \mathrm{~cm}$ de altura, em relação àqueles rebaixados até $10 \mathrm{~cm}$. Assim, qualquer tentativa de aumentar a proporção de remoção da massa de forragem disponível pode comprometer a perenidade do pasto. Pastejos relativamente lenientes, que não ultrapassam uma redução em $50 \%$ da altura do dossel,

Tabela 3. Massa de forragem e componentes morfológicos no pré-pastejo e pós-pastejo, taxa de acúmulo de forragem (TAF) e densidade populacional de perfilhos basilares (DPPb), em pastos do híbrido de Urochloa 'BRS RB331 Ipyporã', submetidos a combinações entre frequências e intensidades de pastejo, em diferentes estações do ano ${ }^{(1)}$.

\begin{tabular}{|c|c|c|c|c|c|c|c|}
\hline Variável & Verão 2012 & Outono 2013 & Inverno 2013 & Primavera 2013 & Verão 2013 & Outono 2014 & $\mathrm{p}$ \\
\hline \multicolumn{8}{|c|}{ Pré-pastejo } \\
\hline Massa de forragem $\left(\mathrm{kg} \mathrm{ha}^{-1} \mathrm{MS}^{-1}\right)$ & $3.984 \mathrm{~A}(106)$ & $3.461 \mathrm{AB}(214)$ & $3.558 \mathrm{AB}(175)$ & $3.142 \mathrm{~B}(155)$ & 3.654AB (151) & $3.597 \mathrm{AB}(161)$ & 0,0013 \\
\hline Folha (\%) & $70 \mathrm{~A}(0,9)$ & $66 \mathrm{~A}(1,9)$ & 57B $(1,6)$ & $73 \mathrm{~A}(1,4)$ & $69 \mathrm{~A}(1,4)$ & $71 \mathrm{~A}(1,5)$ & 0,0001 \\
\hline Colmo $(\%)$ & $20 \mathrm{~A}(0,6)$ & $23 \mathrm{~A}(1,3)$ & $20 \mathrm{~A}(1,1)$ & 14B $(1,0)$ & $20 \mathrm{~A}(0,9)$ & $19 \mathrm{~A}(1,0)$ & 0,0001 \\
\hline Material morto (\%) & 10B $(0,9)$ & 10B $(1,8)$ & $24 \mathrm{~A}(1,5)$ & 13B $(1,3)$ & $11 \mathrm{~B}(1,3)$ & 10B $(1,4)$ & 0,0001 \\
\hline Relação folha:colmo & $3,5 \mathrm{~B}(0,2)$ & $2,7 \mathrm{~B}(0,4)$ & $2,9 \mathrm{~B}(0,3)$ & $5,2 \mathrm{~A}(0,3)$ & $3,5 \mathrm{~B}(0,3)$ & $3,7 \mathrm{~B}(0,3)$ & 0,0001 \\
\hline \multicolumn{8}{|c|}{ Pós-pastejo } \\
\hline Folha (\%) & $21 \mathrm{~A}(1,2)$ & $17 \mathrm{AB}(2,4)$ & $12 \mathrm{~B}(2,0)$ & $20 \mathrm{~A}(1,8)$ & $16 \mathrm{AB}(1,7)$ & $18 \mathrm{AB}(1,8)$ & 0,0105 \\
\hline Colmo (\%) & $31 \mathrm{~A}(1,4)$ & $35 \mathrm{~A}(2,9)$ & 19B $(2,4)$ & $27 \mathrm{AB}(2,1)$ & $30 \mathrm{~A}(2,0)$ & $26 \mathrm{AB}(2,2)$ & 0,0002 \\
\hline Material morto (\%) & 48B $(1,9)$ & 48B $(1,9)$ & $69 \mathrm{~A}(3,2)$ & 53B $(2,9)$ & 53B $(2,8)$ & $56 \mathrm{~B}(3,0)$ & 0,0001 \\
\hline \multicolumn{8}{|c|}{ Taxa de acúmulo } \\
\hline TAF $\left(\mathrm{kg} \mathrm{ha}^{-1}\right.$ de MS dia-1) & $58,7 \mathrm{~A}(1,9)$ & $48,3 \mathrm{~B}(2,8)$ & $13,5 \mathrm{C}(2,3)$ & $19,5 \mathrm{C}(2,1)$ & $60,0 \mathrm{~A}(2,0)$ & 43,7B $(2,1)$ & 0,0001 \\
\hline \multicolumn{8}{|c|}{ Densidade populacional de perfilhos } \\
\hline $\mathrm{DPPb}$ (perfilhos $\mathrm{m}^{-2}$ ) & $1.182 \mathrm{AB}(36)$ & $1.309 \mathrm{~A}(40)$ & $1.045 \mathrm{~B}(49)$ & $1.143 \mathrm{AB}(44)$ & $1.093 \mathrm{~B}(35)$ & $1.007 \mathrm{~B}(76)$ & 0,0002 \\
\hline
\end{tabular}


parecem ser uma condição efetiva para maximizar a velocidade instantânea de ingestão de forragem (Fonseca et al., 2012), sem prejuízos à capacidade de produção do pasto (Zanini et al., 2012). No entanto, cabe ressaltar que a adubação nitrogenada utilizada no presente experimento foi relativamente moderada (150 kg de $\mathrm{N} \mathrm{ha}^{-1}$ por ano) o que poderia ter impactado de forma negativa o processo de recuperação dos pastos, principalmente aqueles manejados com resíduo de $10 \mathrm{~cm}$ de altura. Assim, apesar da importância da área foliar residual no processo de rebrotação dos pastos, é importante salientar que a quantidade de $\mathrm{N}$ aplicado pode ter gerado condições de dosséis com baixos índices de nutrição nitrogenada (Lemaire et al., 2008), o que é uma indicação de que os pastos não dispunham de quantidades suficientes deste nutriente para expressar todo seu potencial produtivo, independentemente de tratamento.

Pastos manejados com 95\% de IL apresentaram valores maiores de densidade populacional de perfilhos basilares (DPPb) do que os pastos manejados com ILmáx (Tabela 2). Estes resultados podem ser explicados por um aumento de competição por luz, o que pode provocar o aumento de mortalidade de perfilhos, um processo conhecido como autodesbaste (Sbrissia et al., 2008). Os maiores valores de DPPb foram observados nos pastos manejados com resíduos mais altos $(15 \mathrm{~cm})$ (Tabela 1). Esse resultado é uma indicação de que o híbrido 'BRS RB331 Ipyporã', aparentemente, apresenta limitações para se adaptar a alturas de resíduos inferiores a $15 \mathrm{~cm}$, independentemente da meta em pré-pastejo. Resultado diferente foi encontrado por Portela et al. (2011), que trabalharam com $U$. decumbens; estes autores observaram que essa espécie é capaz de aumentar sua $\mathrm{DPPb}$ até resíduos de $5 \mathrm{~cm}$ de altura, o que indica uma grande variabilidade genética entre espécies de plantas forrageiras, em relação às estratégias de manejo empregadas.

Uma característica que deve ser considerada é a aparente capacidade de os pastos de 'BRS RB331 Ipyporã' resistirem a variações em DPPb durante o ano (Tabela 3). Mesmo em períodos de baixa disponibilidade de fatores de crescimento, os valores permaneceram acima de 1.000 perfilhos $\mathrm{m}^{-2}$. Provavelmente, os perfilhos gerados durante o período de verão/outono de 2013 permaneceram vivos durante a época da seca, o que garantiu a estabilidade do número de perfilhos ao longo do ano. Durante o inverno e até meados da primavera, a taxa de aparecimento de perfilhos normalmente é muito baixa (Sbrissia et al., 2010), o que é uma indicação de que a estabilidade desta cultivar pode estar associada a uma alta taxa de sobrevivência de perfilhos. Isso pode conferir ao 'BRS RB331 Ipyporã' uma característica de maior resistência a períodos de estresse do que a outras cultivares de Urochloa. Giacomini et al. (2009), em experimento análogo a este, avaliaram U. brizantha 'Marandu' e observaram que as variações meteorológicas durante o estudo provocaram alterações de perfilhamento, no entanto, com variações mais significativas entre as estações do ano, em que a DPPb apresentou redução no início e aumento ao final da primavera, tendo atingido o máximo durante o verão. Além disso, as menores oscilações em DPP podem ser um fator importante, para impedir que plantas invasoras se aproveitem de uma instabilidade populacional transitória e entrem em competição com a gramínea cultivada (Matthew et al., 2000).

Quanto ao valor nutritivo, em pastos manejados com $95 \%$ de IL as folhas apresentaram maior teor de proteína bruta $(\mathrm{PB})$, digestibilidade in vitro da matéria orgânica (DIVMO) e menor teor de fibra em detergente neutro (FDN) do que em pastos manejados com ILmáx (Tabela 4). No componente colmo, pastos manejados com $95 \%$ de IL apresentaram maior teor de $\mathrm{PB}$ e menor de lignina em detergente ácido (LDA), em

Tabela 4. Valor nutritivo de pastos do híbrido de Urochloa 'BRS RB331 Ipyporã', submetidos a combinações entre frequências e intensidades de pastejo ${ }^{(1)}$.

\begin{tabular}{lccc}
\hline Variável & \multicolumn{2}{c}{ Interceptação de luz (IL) } & $\mathrm{p}$ \\
\cline { 2 - 3 } & \multicolumn{2}{c}{$95 \%$} & \multicolumn{2}{c}{ ILmáx } \\
\hline PB (\%) & $13,8 \mathrm{~A}(0,33)$ & $11,9 \mathrm{~B}(0,38)$ & 0,0005 \\
DIVMO (\%) & $69,4 \mathrm{~A}(0,53)$ & $65,6 \mathrm{~B}(0,60)$ & 0,0001 \\
FDN (\%) & $67,9 \mathrm{~B}(0,26)$ & $69,1 \mathrm{~A}(0,29)$ & 0,0027 \\
LDA (\%) & $2,5 \mathrm{~A}(0,04)$ & $2,6 \mathrm{~A}(0,04)$ & 0,0810 \\
\hline \multicolumn{3}{c}{ Colmo } \\
PB (\%) & 8,8A $(0.16)$ & $7,9 \mathrm{~B}(0,19)$ & 0,0001 \\
DIVMO (\%) & $63,4 \mathrm{~A}(0,64)$ & $62,2 \mathrm{~A}(0,73)$ & 0,1550 \\
FDN (\%) & $72,3 \mathrm{~A}(0,59)$ & $73,1 \mathrm{~A}(0,68)$ & 0,3510 \\
LDA (\%) & $3,1 \mathrm{~B}(0,05)$ & $3,3 \mathrm{~A}(0,06)$ & 0,0149 \\
\hline
\end{tabular}

${ }^{(1)}$ Médias seguidas de letras iguais, nas linhas, não diferem pelo teste Tukey, a $5 \%$ de probabilidade. Valores entre parênteses correspondem ao erro-padrão da média. $\mathrm{PB}$, percentual de proteína bruta; DIVMO, percentual de digestibilidade in vitro da matéria orgânica; FDN, percentual de fibra em detergente neutro; e LDA, percentual de lignina em detergente ácido. 
comparação àqueles manejados com ILmáx. Segundo Reis \& Rodrigues (1993), com o avanço da maturidade das plantas, verificam-se aumentos significativos dos teores de carboidratos estruturais e lignina, e redução do conteúdo celular, o que causa diminuição da digestibilidade da forragem. Nave et al. (2010) avaliaram o efeito de diferentes estratégias de pastejo sobre o valor nutricional de pastos de $U$. brizantha 'Xaraés' e observaram que pastos manejados com 95\% de IL apresentaram maior teor de PB na forragem, maior DVIMS na folha e menor teor de FDN no colmo, do que os pastos manejados com $100 \%$ de IL ou com pastejo em intervalo de dias fixos (28 dias).

Em um experimento com capim-tanzânia (Panicum maximum Jacq. 'Tanzânia-1'), Difante et al. (2010) avaliaram o desempenho animal em pastos manejados com 95\% de IL e duas intensidades de pastejo (25 e $50 \mathrm{~cm}$ ). $\mathrm{O}$ valor nutritivo destes pastos apresentaram, na fração folha, valores semelhantes aos encontrados no presente trabalho (PB, 10,5\%; DIVMO, 57,2\%; FDN, 76,6\%; LDA, 3,3\%). Assim, pastos manejados com $50 \mathrm{~cm}$ de altura de resíduo apresentaram maior ganho de massa média diária ( 801 g por dia), e pastos manejados com $25 \mathrm{~cm}$ de altura de resíduo apresentaram maior ganho de massa por área $\left(601 \mathrm{~kg} \mathrm{ha}^{-1}\right)$. De forma análoga, o híbrido 'BRS RB331 Ipyporã' apresenta valores semelhantes quanto ao valor nutritivo aos de algumas cultivares de Panicum maximum e se mostra como alternativa para produtores que possuam animais de categorias com alta exigência nutricional.
Não houve efeito significativo da estação do ano quanto à $\mathrm{PB}(\mathrm{p}=0,2140)$ e à $\mathrm{LDA}(\mathrm{p}=0,513)$ da folha, que tiveram média de 12,9 e $2,5 \%$, respectivamente. A DIVMO no componente folha foi maior no outono de 2014 e menor no verão de 2012. A FDN na folha foi maior no verão de 2012 e menor na primavera de 2013 (Tabela 5). O maior valor de PB no colmo foi observado no outono de 2014 e o menor no inverno de 2014. A FDN do colmo foi maior no verão de 2012 , outono de 2013 e inverno de 2013, e menor na primavera de 2013 e outono de 2014. O maior teor de LDA do colmo foi observado no inverno de 2013, e o menor, no verão de 2013. Euclides et al. (2009) avaliaram diferentes pastos de U. brizantha ('Marandu', 'Xaraés' e 'Piatã'), manejados sob pastejo alternado, e observaram, na porção folha, o menor teor de PB ( $8,2 \%$ nas três cultivares), e menor percentual de DIVMO (53,2, 50,1 e 48,7\%, 'Marandu', 'Xaraés' e 'Piatã', respectivamente), em relação aos encontrados no presente trabalho.

Os resultados de valor nutritivo, observados no presente experimento para 'BRS RB331 Ipyporã', podem ser atribuídos à influência genética de um dos seus genitores, a $U$. ruziziensis que, segundo Lopes et al. (2010), apresenta melhor qualidade nutricional do que outras espécies do gênero Urochloa, como $U$. decumbens, $U$. humidicola e $U$. brizantha. Assim, é possível inferir que o híbrido de Urochloa 'BRS RB331 Ipyporã' pode ser considerado uma importante alternativa forrageira para sistemas de produção animal baseado em pastagens.

Tabela 5. Valor nutritivo de pastos do híbrido de Urochloa 'BRS RB331 Ipyporã', submetidos a combinações entre frequências e intensidades de pastejo, em diferentes estações do ano ${ }^{(1)}$.

\begin{tabular}{|c|c|c|c|c|c|c|c|}
\hline Variável & Verão 2012 & Outono 2013 & Inverno 2013 & Primavera 2013 & Verão 2013 & Outono 2014 & $\mathrm{p}$ \\
\hline \multicolumn{8}{|c|}{ Folha } \\
\hline PB (\%) & $11,9 \mathrm{~A}(0,52)$ & $13,5 \mathrm{~A}(0,58)$ & $12,8 \mathrm{~A}(0,84)$ & $13,8 \mathrm{~A}(0,66)$ & $11,8 \mathrm{~A}(0,77)$ & $13,5 \mathrm{~A}(0,70)$ & 0,2140 \\
\hline DIVMO (\%) & $64,1 \mathrm{D}(0,85)$ & $67,9 \mathrm{ABC}(0,90)$ & $68,3 \mathrm{AB}(1,13)$ & $68,0 \mathrm{AB}(1,00)$ & $66,2 \mathrm{BCD}(1,00)$ & $70,5 \mathrm{~A}(1,00)$ & 0,0002 \\
\hline FDN (\%) & $70,6 \mathrm{~A}(0,41)$ & $68,7 \mathrm{~B}(0,44)$ & $70,5 \mathrm{AB}(0,55)$ & $63,4 \mathrm{C}(0,49)$ & $69,4 \mathrm{AB}(0,47)$ & $68,4 \mathrm{~B}(0,49)$ & 0,0001 \\
\hline LDA (\%) & $2,9 \mathrm{~A}(0,06)$ & $2,7 \mathrm{~A}(0,06)$ & $2,5 \mathrm{~A}(0,08)$ & $2,6 \mathrm{~A}(0,07)$ & $2,2 \mathrm{~A}(0,07)$ & $2,5 \mathrm{~A}(0,07)$ & 0,1032 \\
\hline \multicolumn{8}{|c|}{ Colmo } \\
\hline PB (\%) & $7,6 \mathrm{CD}(0,26)$ & $9,3 \mathrm{AB}(0,28)$ & $7,0 \mathrm{D}(0,35)$ & $8,4 \mathrm{BC}(0,31)$ & $7,7 \mathrm{CD}(0,30)$ & $10,2 \mathrm{~A}(0,31)$ & 0,0001 \\
\hline DIVMO (\%) & $57,2 \mathrm{C}(1,02)$ & $64,0 \mathrm{~B}(1,10)$ & $60,5 \mathrm{BC}(1,37)$ & $60,5 \mathrm{BC}(1,21)$ & $64,2 \mathrm{~B}(1,18)$ & $70,9 \mathrm{~A}(1,21)$ & 0,0001 \\
\hline FDN (\%) & $74,8 \mathrm{~A}(0,95)$ & $75,5 \mathrm{~A}(1,02)$ & $74,7 \mathrm{~A}(1,27)$ & $68,9 \mathrm{~B}(1,13)$ & $73,1 \mathrm{AB}(1,10)$ & $69,3 \mathrm{~B}(1,13)$ & 0,0001 \\
\hline LDA $(\%)$ & $3,4 \mathrm{BC}(0,08)$ & $3,5 \mathrm{AB}(0,08)$ & $3,8 \mathrm{~A}(0,10)$ & $3,1 \mathrm{CD}(0,09)$ & $2,7 \mathrm{E}(0,09)$ & $2,9 \mathrm{DE}(0,09)$ & 0,0001 \\
\hline
\end{tabular}

${ }^{(1)}$ Médias seguidas de letras iguais, nas linhas, não diferem pelo teste Tukey, a $5 \%$ de probabilidade. Valores entre parênteses correspondem ao erro-padrão da média. PB, percentual de proteína bruta; DIVMO, percentual de digestibilidade in vitro da matéria orgânica; FDN, percentual de fibra em detergente neutro; e LDA, percentual de lignina em detergente ácido. 


\section{Conclusões}

Pastos do híbrido interespecífico de Urochloa 'BRS RB331 Ipyporã' apresentam maior acúmulo de forragem e maiores teores de proteína bruta e digestibilidade in vitro da matéria orgânica e menores teores de fibra em detergente neutro, na fração folha, quando manejados com $95 \%$ de interceptação da luz na condição de pré-pastejo, com altura de dossel $30 \mathrm{~cm}$, associada a $15 \mathrm{~cm}$ de altura de resíduo.

\section{Agradecimentos}

Ao Conselho Nacional de Desenvolvimento Científico e Tecnológico (CNPq), à Fundação de Apoio ao Desenvolvimento do Ensino, Ciência e Tecnologia do Estado de Mato Grosso do Sul (Fundect) e à Embrapa Gado de Corte, e pelo apoio financeiro para a execução da pesquisa; à Coordenação de Aperfeiçoamento de Pessoal de Nível Superior (Capes), pela concessão de bolsas.

\section{Referências}

BARBOSA, R.A.; NASCIMENTO JÚNIOR, D. do; EUCLIDES, V.P.B.; SILVA, S.C. da; ZIMMER, A.H.; TORRES JÚNIOR, R.A. de A. Capim-tanzânia submetido a combinações entre intensidade e frequência de pastejo. Pesquisa Agropecuária Brasileira, v.42, p.329-340, 2007. DOI: 10.1590/S0100-204X2007000300005.

BERONE, G.D.; LATTANZI, F.A.; COLABELLI, M.R.; AGNUSDEI, M.G. A comparative analysis of the temperature response of leaf elongation in Bromus stamineus and Lolium perenne plants in the field: intrinsic and size-mediated effects. Annals of Botany, v.100, p.813-820, 2007. DOI: 10.1093/aob/ mem 174 .

BRASIL. Ministério da Agricultura, Pecuária e Abastecimento. Cultivarweb: gerenciamento de informação: Serviço Nacional de Proteção de Cultivares - SNPC. Brasília, [2015]. Disponível em: $\quad<$ http://extranet.agricultura.gov.br/php/snpc/cultivarweb/ cultivares protegidas.php>. Acesso em: 4 fev. 2016.

CARNEVALLI, R.A.; SILVA, S.C. da; BUENO, A.A.O.; UEBELE, M.C.; HODGSON, J.; SILVA, G.N.; MORAIS, J.P.G. Herbage production and grazing losses in Panicum maximum cv. Mombaça under four grazing managements. Tropical Grasslands, v.40, p.165-176, 2006.

DIFANTE, G. dos S.; EUCLIDES, V.P.B.; NASCIMENTO JÚNIOR, D. do; SILVA, S.C. da; BARBOSA, R.A.; TORRES JÚNIOR, R.A. de A. Desempenho e conversão alimentar de novilhos de corte em capim-tanzânia submetido a duas intensidades de pastejo sob lotação rotativa. Revista Brasileira de Zootecnia, v.39, p.33-41, 2010. DOI: 10.1590/ S1516-35982010000100005.
EUCLIDES, V.P.B.; MACEDO, M.C.M.; VALLE, C.B. do; DIFANTE, G. dos S.; BARBOSA, R.A.; CACERE, E.R. Valor nutritivo da forragem e produção animal em pastagens de Brachiaria brizantha. Pesquisa Agropecuária Brasileira, v.44, p.98-106, 2009. DOI: 10.1590/S0100-204X2009000100014.

FONSECA, L.; MEZZALIRA, J.C.; BREMM, C.; FILHO, R.S.A.; GONDA, H.L.; CARVALHO, P.C. de F. Management targets for maximising the short-term herbage intake rate of cattle grazing in Sorghum bicolor. Livestock Science, v.145, p.205-211, 2012. DOI: 10.1016/j.livsci.2012.02.003.

GIACOMINI, A.A.; SILVA, S.C. da; SARMENTO, D.O. de L.; ZEFERINO, C.V.; TRINDADE, J.K. da; SOUZA JÚNIOR, S.J.; GUARDA, V. del'A.; SBRISSIA, A.F.; NASCIMENTO JÚNIOR, D. do. Components of the leaf area index of marandu palisadegrass swards subjected to strategies of intermittent stocking. Scientia Agricola, v.66, p.721-732, 2009. DOI: 10.1590/ S0103-90162009000600002.

LEMAIRE, G.; JEUFFROY, M.-H.; GASTAL, F. Diagnosis tool for plant and crop $\mathrm{N}$ status in vegetative stage: theory and practices for crop N management. European Journal of Agronomy, v.28, p.614-624, 2008. DOI: 10.1016/j.eja.2008.01.005.

LOPES, F.C.F.; PACIULLO, D.S.C; MOTA, E.F; PEREIRA, J.C; AZAMBUJA, A.A; MOTTA, A.C.S; RODRIGUES, G.S; DUQUE, A.C.A. Composição química e digestibilidade ruminal in situ da forragem de quatro espécies do gênero Brachiaria. Arquivo Brasileiro de Medicina Veterinária e Zootecnia, v.62, p.883-888, 2010. DOI: 10.1590/S0102-09352010000400018.

MATTHEW, C.; ASSUERO, S.G.; BLACK, C.K.; HAMILTON, N.R.S. Tiller dynamics of grazed swards. In: LEMAIRE, G.; HODGSON, J.; MORAES, A. de; CARVALHO, P.C. de F.; NABINGER, C. (Ed.). Grassland ecophysiology and grazing ecology. Wallingford: CABI, 2000. p.127-150. DOI: 10.1079/9780851994529.0127.

MATTHEW, C.; LEMAIRE, G.; SACKVILLE HAMILTON, N.R.; HERNANDEZ-GARAY, A. A modified self-thinning equation to describe size/density relationships for defoliated swards. Annals of Botany, v.76, p.579-587, 1995. DOI: 10.1006/anbo.1995.1135.

NAVE, R.L.G.; PEDREIRA, C.G.S.; PEDREIRA, B.C. Nutritive value and physical characteristics of Xaraes palisadegrass as affected by grazing strategy. South African Journal of Animal Science, v.40, p.285-293, 2010.

ORR, R.J.; RUTTER, S.M.; YARROW, N.H.; CHAMPION, R.A.; ROOK, A.J. Changes in ingestive behaviour of yearling dairy heifers due to changes in sward state during grazing down of rotationally stocked ryegrass or white clover pastures. Applied Animal Behaviour Science, v.87, p.205-222, 2004. DOI: 10.1016/j.applanim.2004.01.009.

PEDREIRA, B.C. e; PEDREIRA, C.G.S.; SILVA, S.C. da. Acúmulo de forragem durante a rebrotação de capim-xaraés submetido a três estratégias de desfolhação. Revista Brasileira de Zootecnia, v.38, p.618-625, 2009. DOI: 10.1590/S1516-35982009000400005.

PORTELA, J.N.; PEDREIRA, C.G.S.; BRAGA, G.J. Demografia e densidade de perfilhos de capim-braquiária sob pastejo em lotação intermitente. Pesquisa Agropecuária Brasileira, v.46, p.315-322, 2011. DOI: 10.1590/S0100-204X2011000300013. 
REIS, R.A.; RODRIGUES, L.R. de A. Valor nutritivo de plantas forrageiras. Jaboticabal: FCAV-UNESP: FUNEP, 1993.

SANTOS, H.G. dos; JACOMINE, P.K.T.; ANJOS, L.H.C. dos; OLIVEIRA, V.A. de; LUMBRERAS, J.F.; COELHO, M.R.; ALMEIDA, J.A. de; CUNHA, T.J.F.; OLIVEIRA, J.B. de. Sistema brasileiro de classificação de solos. 3.ed. rev. e ampl. Brasília: Embrapa, 2013. 353p.

SBRISSIA, A.F.; SILVA, S.C. da; SARMENTO, D.O.L.; MOLAN, L.K.; ANDRADE, F.M.E.; GONÇALVES, A.C.; LUPINACCI, A.V. Tillering dynamics in palisadegrass swards continuously stocked by cattle. Plant Ecology, v.206, p.349-359, 2010. DOI: $10.1007 / \mathrm{s} 11258-009-9647-7$.

SBRISSIA, A.F.; SILVA, S.C. da. Compensação tamanho/ densidade populacional de perfilhos em pastos de capim-marandu.
Revista Brasileira de Zootecnia, v.37, p.35-47, 2008. DOI: 10.1590/S1516-35982008000100005.

TRINDADE, J.K. da; SILVA, S.C. da; SOUZA JÚNIOR, S.J. de; GIACOMINI, A.A.; ZEFERINO, C.V.; GUARDA, V.D.A.; CARVALHO, P.C. de F. Composição morfológica da forragem consumida por bovinos de corte durante o rebaixamento do capim-marandu submetido a estratégias de pastejo rotativo. Pesquisa Agropecuária Brasileira, v.42, p.883-890, 2007. DOI: 10.1590/S0100-204X2007000600016.

ZANINI, G.D.; SANTOS, G.T.; SBRISSIA, A.F. Frequencies and intensities of defoliation in Aruana Guineagrass swards: accumulation and morphological composition of forage. Revista Brasileira de Zootecnia, v.41, p.905-913, 2012. DOI: 10.1590/ S1516-35982012000400011.

$\overline{\text { Recebido em } 13 \text { de fevereiro de } 2016 \text { e aprovado em } 17 \text { de maio de } 2016}$ 